\title{
Asthma as a link between chest illness in childhood and chronic cough and phlegm in young adults
}

\begin{abstract}
The link between chest illnesses in childhood to age 7 and the prevalence of cough and phlegm in the winter reported at age 23 was investigated in a cohort of 10557 British children born in one week in 1958 (national child development study). Both pneumonia and asthma or wheezy bronchitis to age 7 were associated with a significant excess in the prevalence of chronic cough and phlegm at age $\mathbf{2 3}$ after controlling for current smoking. This excess was largely attributable to the association of cough and phlegm at age 23 with a history of asthma or wheezy bronchitis from age 16. When adjustment was made for recent wheezing, current cigarette consumption, previous smoking habit, and passive exposure to smoke the relative odds of cough or phlegm, or both, in subjects with a history of childhood chest illness was $1 \cdot 11$ ( $95 \%$ confidence interval 0.97 to 1.27 ). When analysed separately asthma, wheezy bronchitis, and pneumonia up to age 7 did not significantly increase the prevalence of either cough or phlegm.
\end{abstract}

The explanation for the observed continuity between chest illness in childhood and respiratory symptoms in later life may lie more in the time course of functional disturbances related to asthma than in the persistence of structural lung damage.

\section{Introduction}

Deaths from respiratory disease in infancy and in middle age show similar patterns with respect to social class, urban or rural area, and region of residence. ${ }^{12} \mathrm{~A}$ similar relation was found between respiratory symptoms in children of primary school age and mortality from bronchitis in adults. ${ }^{3}$ These observations led to the theory that chronic respiratory disease in adults may have its origins in childhood and, more specifically, that early episodes of lower respiratory illness may be causally related to chronic bronchitis in middle age..$^{1-3}$

Because the recall of respiratory problems in childhood is likely to be influenced by current symptoms experienced by adult respondents ${ }^{4}$ the case for respiratory disease in childhood continuing into later life has rested heavily on the follow up of British children born in 1946 (the national survey of health and development). Colley et al found that a history of lower respiratory infection (bronchitis, bronchopneumonia, or pneumonia) obtained from parents when their child was 2 was associated with a higher prevalence of cough during the winter at age 20, independent of the subject's smoking habits, paternal social class, and exposure to air

Department of Community Medicine, Medical School, University of Edinburgh EH8 9AG

D P STRACHAN, MRCP, MRCGP, Wellcome research training fellow in clinical epidemiology

Department of Clinical Epidemiology and Social Medicine, St George's Hospital Medical School, London

H R ANDERSON, MD, FFCM, professor

J M BLAND, PHD, senior lecturer in medical statistics

Department of Paediatric Epidemiology, Institute of Child Health, London C PECKHAM, MD, FFCM, professor

Correspondence to: Dr D P Strachan, Department of Epidemiology, London School of Hygiene and Tropical Medicine, London WC1E 7HT. pollution. ${ }^{5}$ The effect was greater when the same cohort was contacted again at the age of $25^{6}$ and persisted at 36 , although no significant effect on peak expiratory flow rate was found. ${ }^{7}$ In another small longitudinal study "catarrhal" children had more respiratory symptoms in early middle age than their peers but lung function was similar. ${ }^{8}$

Prospective studies of wheezy children in Melbourne led to reassessment of the nature of childhood "bronchitis" and indicated that asthma and bronchitis with wheezing may be regarded as part of the same syndrome. ${ }^{9-12}$ Although many wheezy children subsequently become free of symptoms, ${ }^{910}$ those who do not are at increased risk of cough and phlegm in their early 20s. ${ }^{12}$ This suggested an alternative explanation of the link between childhood and adult respiratory disease: that they are connected through persistence of the wheezing tendency. ${ }^{13}$

The follow up to age 23 of a second British cohort, born in 1958 (the national child development study), offered the opportunity to re-examine the relation between respiratory disease in childhood and symptoms of chronic bronchitis in young adults. Information on asthma and wheezy bronchitis, which was not reported for the 1946 cohort, allowed respiratory problems that were associated with a wheezing tendency to be distinguished from those that were not.

\section{Methods}

We obtained data from the national child development study, which is a follow up study of all children born in Britain during one week in March 1958; these children formed the study population for the perinatal mortality survey. ${ }^{14}$ The children were examined at the ages of 7,11 , and 16; the methods used have been discussed in detail elsewhere. ${ }^{15-17}$ In 1981, when the subjects were 23 , an attempt was made to trace and interview all those who were resident in the United Kingdom. ${ }^{18}$ At the follow up at age 7 the parents were interviewed by health visitors and asked the following questions: Has your child ever had attacks of asthma? Has your child ever had attacks of bronchitis with wheezing? Has your child ever had pneumonia? If so, at what age did the first attack occur?

In 1981, when the age of the cohort was 23, the subjects themselves were given a 90 minute interview by staff from a commercial market research organisation. The following questions, including four derived from the Medical Research Council's questionnaire on respiratory symptoms, ${ }^{19}$ were asked: Since your 16th birthday have you had an attack of asthma or wheezy bronchitis? If so, have you had an attack in the past 12 months? Do you usually cough first thing in the morning in the winter? Do you usually cough during the day or at night in the winter? Do you usually bring up any phlegm from your chest first thing in the morning in the winter? Do you usually bring up any phlegm from the chest during the day or at night in the winter? The interview did not include questions on the duration of cough and phlegm, which are used to define chronic bronchitis in older adults. ${ }^{20}$ Further questions were asked about current and past cigarette smoking and the presence of other smokers in the home.

In the analysis no distinction was made between asthma and wheezy bronchitis in the first seven years of life as these conditions were not distinguished in the questionnaire given to the young adults. As one of the principal associations of respiratory symptoms is with cigarette smoking this was controlled for in the analysis; in cross tabulations the cohort was divided into smokers and non-smokers according to smoking habit at age 23, and the sample was then stratified into those who did and did not report attacks of asthma or wheezy bronchitis from age 16. Multiple logistic regression models were used to control more rigorously for the effects of active and passive smoking and recent wheezing episodes. The generalised linear interactive modelling statistical package ${ }^{21}$ was used to fit separate models with the outcome variable being, in turn, cough or phlegm, or both; cough alone; and phlegm alone. For subjects who smoked these models included the daily cigarette consumption $(0-9,10-19,20-29,30$ and over $)$, and for 
non-smokers the models included whether they had ever smoked a cigarette, cigar, or pipe at any time; whether they had ever smoked regularly (at least one cigarette a day for a year or more); and whether they were currently living with a smoker. The effect of recent wheezing episodes was controlled for in the regression analysis with three categories: no asthma or wheezy bronchitis from age 16; asthma or wheezy bronchitis from age 16 but not in the past year at age 23; and asthma or wheezy bronchitis in the past year at 23. The effects of any chest illness, asthma or wheezy bronchitis alone, and pneumonia alone by age 7 were investigated in separate models.

\section{Results}

We obtained information on respiratory symptoms and smoking habits at age 23 and on chest illnesses in childhood for 6268 non-smokers and 4289 smokers, comprising $72 \%$ of the 14571 children who had been available for follow up at age 7 and for whom data on respiratory illness were available and $63 \%$ of the 16883 survivors in the perinatal mortality survey. Comparison of responders and non-responders in earlier studies of the cohort has shown that the prevalence of respiratory symptoms was not substantially biased by losses to follow up. ${ }^{22} 23$

Table I shows the relation between pneumonia and asthma or wheezy bronchitis in childhood and wheezing at ages 16 to 23 . Overall $1899(18 \%)$ of the cohort were reported as having had asthma or wheezy bronchitis in the first seven years of life, of whom 207 (2\%) also had a history of pneumonia; a further $260(2 \cdot 5 \%)$ had had pneumonia but not asthma or wheezy bronchitis. subdivided according to whether they had recent wheeze the association was reduced, confirming that recent asthma or wheezy bronchitis might partially explain the relation between chest illness in childhood and respiratory symptoms in young adults.

Table IV shows the effect of recent wheezing episodes on the relations between cough and phlegm at age 23 and pneumonia, asthma, and wheezy bronchitis in childhood analysed by multiple logistic regression. When recent asthma or wheezy bronchitis was excluded (controlling only for active and passive smoking) the association between chest illness in childhood and adult respiratory symptoms was highly significant overall and for cough and phlegm separately. The effect of pneumonia in childhood on respiratory symptoms in young adults was less than that of asthma or wheezy bronchitis; because the numbers of children with pneumonia were fairly small the confidence intervals were wide and included unity.

When a history of asthma or wheezy bronchitis from age 16 was included in the models the effects of chest illness in childhood were no longer significant at the $5 \%$ level but still showed the same trend, with cough and phlegm being more common among subjects with a history of pneumonia, asthma, or wheezy bronchitis in childhood. The upper confidence limits for these odds ratio estimates were all below $1 \cdot 5$, suggesting that long term sequelae of chest illnesses in childhood in subjects without recent wheeze are unlikely to be important determinants of cough and phlegm in early adulthood (table IV). In contrast, there was a pronounced effect of recent asthma or wheezy bronchitis on cough and phlegm at age 23 , which was independent of both smoking and childhood illness $\left(\chi^{2}=351 \cdot 0,2 \mathrm{df}\right)$. Comparison of the estimates of odds ratios from models controlling for

TABLE I-Number (percentage) of subjects with asthma or wheezy bronchitis at age 23 by asthma or wheezy bronchitis and pneumonia to age 7

\begin{tabular}{lrrrr}
\hline & \multicolumn{4}{c}{ Asthma or wheezy bronchitis: } \\
\cline { 2 - 5 } & $\begin{array}{c}\text { In past year at } \\
\text { age 23 }\end{array}$ & $\begin{array}{c}\text { From age 16, but } \\
\text { not at age 23 }\end{array}$ & $\begin{array}{c}\text { None from } \\
\text { age 16 }\end{array}$ & Total \\
\hline Pneumonia and asthma or wheezy bronchitis by age 7 & $\begin{array}{r}25(12) \\
8(3)\end{array}$ & $\begin{array}{c}30(14) \\
16(6)\end{array}$ & $\begin{array}{r}152(73) \\
236(91)\end{array}$ & $207(100)$ \\
Pneumonia only by age 7 & $160(9)$ & $170(10)$ & $1362(80)$ & $1692(100)$ \\
Asthma or wheezy bronchitis only by age 7 & $261(3)$ & $327(4)$ & $7810(93)$ & $8398(100)$ \\
No chest illness by age 7 & $454(4)$ & $543(5)$ & $9560(91)$ & $10557(100)$ \\
\hline Total & & & &
\end{tabular}

Of those subjects with a history of asthma or wheezy bronchitis by age 7, 385 $(20 \%)$ reported a wheezing episode between 16 and $23,185(10 \%)$ reporting asthma or wheezy bronchitis in the past year. Of those with no history of asthma or wheezy bronchitis in early childhood, $612(7 \%)$ reported an episode from age 16. There was a close association between pneumonia and wheezing in childhood; 207 (44\%) of the 467 subjects with a history of pneumonia had also had asthma or wheezy bronchitis by age 7 . Among subjects who did not have asthma or wheezy bronchitis in childhood, however, pneumonia was a poor predictor of subsequent wheezing at 16-23 (table I). The subjects with a history of pneumonia in childhood were more likely to report cough or phlegm at age 23 , but this was not related to their age at the first attack (table II). No distinction was therefore made between pneumonia occurring at different ages in the subsequent analyses.

A history of cough or phlegm at age 23 was strongly associated with recent asthma or wheezy bronchitis (table III). Among smokers the reported prevalence was $56 \%$ for those with wheeze from age 16 and $26 \%$ for those without, and the prevalence among non-smokers was $26 \%$ and $7 \%$, respectively. The extent to which any association between chest illness in childhood and respiratory symptoms in young adults could be explained by the persistence of a wheezing tendency was assessed, given the powerful influence of recent wheeze on the prevalence of reported cough and phlegm.

Table III shows that a history of chest illness in childhood was indeed associated with an increased prevalence of cough or phlegm, or both, at age 23 among both smokers and non-smokers. When the subjects were further smoking alone and for both smoking and asthma or wheezy bronchitis from age 16 confirmed that recent wheezing explained a substantial part of the association between chest illness in childhood and cough and phlegm in young adults (table IV).

\section{Discussion}

The questions about cough and phlegm which were asked in this study were also used in the follow up of the 1946 national survey of health and development cohort at ages 20,25 , and $36 .^{5-7}$ In that cohort, however, the occurrence of "bronchitis, bronchopneumonia, or pneumonia" was assessed at the age of 2 , whereas in our 1958 cohort pneumonia was distinguished from "bronchitis with wheezing" but there was no information about other forms of bronchitis. The study of the 1958 cohort has the advantage of including a more comprehensive assessment of wheezing illness and a larger sample.

Comparison of parental reports of respiratory diseases in their child's first year of life with general practice records suggests that, although specific diagnostic categories show a poor correlation, the disparity is reduced if all diseases of the lower respiratory tract are

TABLE II-Percentage prevalence of cough or phlegm at age 23 in relation to history of pneumonia to age 7 . Figures in parentheses are numbers of subjects

\begin{tabular}{|c|c|c|c|c|c|c|c|}
\hline & \multirow{2}{*}{$\begin{array}{l}\text { No history of } \\
\text { pneumonia }\end{array}$} & \multirow{2}{*}{$\begin{array}{c}\text { Pneumonia at any } \\
\text { age to } 7\end{array}$} & \multicolumn{4}{|c|}{ Age at first attack of pneumonia (years) } & \multirow[b]{2}{*}{ All subjects } \\
\hline & & & $<1$ & 1 & $2-4$ & $5-7$ & \\
\hline $\begin{array}{l}\text { Smokers } \\
\text { Non-smokers }\end{array}$ & $\begin{array}{c}29(1190 / 4088) \\
9(511 / 6002)\end{array}$ & $\begin{array}{l}34(68 / 201) \\
12(33 / 266)\end{array}$ & $\begin{array}{l}29(20 / 68) \\
14(13 / 96)\end{array}$ & $\begin{array}{l}43(15 / 35) \\
11(4 / 37)\end{array}$ & $\begin{array}{l}33(19 / 57) \\
15(10 / 69)\end{array}$ & $\begin{array}{c}34(14 / 41) \\
9(6 / 64)\end{array}$ & $\begin{array}{c}29(1258 / 4289) \\
9(544 / 6268)\end{array}$ \\
\hline
\end{tabular}


TABLE III-Percentage prevalence of cough or phlegm, or both, at age 23 by chest illness in childhood, controlling for smoking and asthma or wheezy bronchitis from age 16 . Figures in parentheses are numbers of subjects

\begin{tabular}{|c|c|c|c|c|c|c|}
\hline & \multicolumn{2}{|c|}{ Asthma or wheezy bronchitis from age 16} & \multicolumn{2}{|c|}{ No asthma or wheezy bronchitis from age 16} & \multicolumn{2}{|c|}{ All subjects } \\
\hline & Smoker & Non-smoker & Smoker & Non-smoker & Smoker & Non-smoker \\
\hline $\begin{array}{l}\text { Pneumonia, asthma, or wheezy bronchitis by age } 7 \\
\text { No chest illness by age } 7\end{array}$ & $\begin{array}{l}57(106 / 186) \\
56(166 / 299)\end{array}$ & $\begin{array}{l}26(57 / 223) \\
29(83 / 289)\end{array}$ & $\begin{array}{l}28(200 / 706) \\
25(786 / 3098)\end{array}$ & $\begin{array}{l}8(83 / 1044) \\
7(321 / 4712)\end{array}$ & $\begin{array}{l}34(306 / 892) \\
28(952 / 3397)\end{array}$ & $\begin{array}{r}11(140 / 1267) \\
8(404 / 5001)\end{array}$ \\
\hline All subjects & $56(272 / 485)$ & $27(140 / 512)$ & $26(986 / 3804)$ & $7(404 / 5756)$ & $29(1258 / 4289)$ & $9(544 / 6268)$ \\
\hline
\end{tabular}

TABLE IV-Relative odds (odds ratio) estimates (and 95\% confidence intervals) derived from multiple logistic regression models for cough and phlegm at age 23, controlling for smoking and recent wheeze, in relation to respiratory disease to age 7

\begin{tabular}{llrr}
\hline \multicolumn{1}{c}{ Outcome variable } & \multicolumn{1}{c}{ Explanatory variable } & \multicolumn{1}{c}{ Controlling for: } \\
\cline { 3 - 4 } & & Smoking only & Smoking and recent wheeze \\
\hline
\end{tabular}

All goodness of fit $\chi^{2}$ values have one degree of freedom.

^Asthma, wheezy bronchitis, or pneumonia.

combined. ${ }^{24}$ One quarter of the children born in 1946 were reported to have suffered from a lower respiratory infection in the first two years of life. ${ }^{5}$ Although the declining infant mortality from respiratory diseases suggests that the incidence of pneumonia among infants born in 1946 may have been higher than that in those born 12 years later, it is unlikely to have accounted for such a high cumulative incidence of respiratory disease. Instead, many children reported as suffering from "bronchitis, bronchopneumonia, or pneumonia" probably had illnesses associated with wheezing, which has been a common presentation in British children during the first few years of life over the past four decades. ${ }^{25-27}$

Our study confirms previous reports that young adults with asthma are particularly prone to symptoms that are normally thought to indicate chronic bronchitis ${ }^{12}$; a history of recent wheezing episodes was as important as smoking in its effect on the prevalence of reported cough and phlegm. This might be due partly to a tendency of some subjects to overreport all kinds of respiratory symptoms, particularly as the questions about cough and phlegm followed those about asthma and wheezy bronchitis. Alternatively, some patients with asthma who report phlegm may have allergic bronchitis with eosinophilic sputum rather than chronic bronchitis with hypersecretion of mucus. ${ }^{12}$ Chronic cough, particularly at night, may be a manifestation of allergic bronchitis and bronchial hyperreactivity even when wheeze is absent. ${ }^{28} 29$

Our results confirm the association between chest illness in childhood and respiratory symptoms in young adults that was evident among the 1946 cohort. ${ }^{5-7}$ Analysis of the 1946 cohort did not take into account the close association of cough and phlegm with wheezing in young adults. Our analysis shows that if this is done the association between chest illness in childhood and adult respiratory symptoms can be almost entirely attributed to the persistence in some subjects of the asthmatic trait. This supports the theory proposed recently ${ }^{13} 30$ that respiratory disease persisting throughout childhood and adolescence may owe more to the disturbances of airways function associated with asthma than to structural damage to the lung caused by respiratory infection in infancy, as implied by earlier workers ${ }^{13}$ and reasserted in a recent study of mortality statistics. ${ }^{2}$ If structural lung damage was important we might have expected pneumonia to be more strongly associated than wheezing in childhood with subsequent cough and phlegm. In fact the opposite was found.

The strong relation between a history of pneumonia and childhood wheezing has various explanations; the most likely is that children with an asthmatic trait are more likely to have infections of the lower respiratory tract or to be more seriously affected by such infections. ${ }^{223}$ In studies of the sequelae of whooping cough, which is a prolonged illness sometimes complicated by collapse of the lung, the most likely explanation for the observed association with subsequent wheezing illness was considered to be a common association with the asthmatic trait. ${ }^{31}$ Although subsequent wheezing and bronchial hyperreactivity are more common among children admitted to hospital with infections of the lower respiratory tract in infancy, these sequelae are not confined to any one diagnostic category. ${ }^{32}$ This argues against the suggestion that specific infectious agents, such as respiratory syncytial virus, cause asthma.$^{33}$

Because this study was confined to assessment by questionnaire only symptoms normally associated with hypersecretion of mucus could be measured. These are poor predictors of mortality compared with spirometric evidence of airflow obstruction, ${ }^{34}$ and ventilatory function needs to be assessed in further studies of this cohort if the role of early respiratory illnesses in the aetiology of chronic obstructive airways disease is to be better understood. The association of a wheezing tendency with both cough and phlegm and reduced peak expiratory flow rate in young adults could be usefully incorporated into the continuing analysis of this topic in the 1946 cohort. $^{35}$

We acknowledge the Wellcome Trust's support of DPS and thank the national child development study's user support group and the Economic and Social Research Council's data archive for their help in accessing the national child development study's database. 


\section{References}

1 Reid DD. The beginnings of bronchitis. Proceedings of the Royal Society of Medicine 1969;62: 311-6.

2 Barker DJP, Osmond C. Childhood respiratory infection and adult chronic bronchitis in England and Wales. Br Med f 1986;293:1271-5.

3 Colley JRT, Reid DD. The urban and social origins of childhood bronchitis in England and Wales. BrMed f 1970;ii:213-7.

4 Burrows B, Knudson RJ, Lebowitz MD. The relationship of childhood respiratory illness to adult obstructive airways disease. Am Rev Respir Dis 1977;115:751-60.

5 Colley JRT, Douglas JWB, Reid DD. Respiratory disease in young adults: influence of early childhood lower respiratory tract illness, social class, air pollution, and smoking. $\mathrm{Br} \mathrm{Med} \mathcal{J}$ 1973;iii:195-8.

6 Kiernan KE, Colley JRT, Douglas JWB, Reid DD. Chronic cough in young adults in relation to smoking habits, childhood environment and chest illness. Respiration 1976;33:236-44.

7 Britten N, Wadsworth J. Long term respiratory sequelae of whooping cough in a nationally representative sample. BrMed f 1986;292:441-4.

representative sample. Br Med f 1986;292:441-4.
8 Harnett RWF, Mair A. Chronic bronchitis and the catarrhal child. Scot Med f 1963;8:175-84.

8 Harnett RWF, Mair A. Chronic bronchitis and the catarrhal child. Scot Med f 1963;8:175-84. asthma in children. An epidemiological study. Br Med f 1969;iv:321-5.

10 Martin AJ, McLennan LA, Landau LI, Phelan PD. Natural history of childhood asthma to adult life. BrMed F 1980;280:1397-1400.

11 Martin AJ, Landau LI, Phelan PD. Lung function in young adults who had asthma in childhood. Am Rev Respir Dis 1980;122:609-16.

12 Martin AJ, Landau LI, Phelan PD. Asthma from childhood at age 21: the patient and his disease. BrMed f 1982;284:380-2.

13 Phelan PD. Does adult chronic obstructive lung disease really begin in childhood? $\mathrm{Br} \mathcal{F}$ Dis Chest 1984;78:1-9.

14 Butler NR, Bonham DG. Perinatal mortality. First report of the 1958 British perinatal mortality survey, under the auspices of the National Birthday Trust Fund. Edinburgh: Livingstone, 1963.

survey, under the auspices of the National Birthday Trust Fund. Edinburgh: Livingstone, 1963.
15 Davie $\mathrm{R}$, Butler N, Goldstein H. From birth to seven. The second report of the national child development study (1958 cohort). London: Longman, 1972.

16 Fogelman K, ed. Britain's sixteen-year-olds. London: National Children's Bureau, 1976.

17 Fogelman K, ed. Growing up in Great Britain: papers from the national child development study. London: MacMillan, 1983.

18 Shepherd P. The national child development study; an introduction to the origins of the study and the methods of data collection. London: NCDS User Support Group, City University, 1986.
19 Medical Research Council. Questionnaire on respiratory symptoms. London: Medical Research Council, 1966.

20 Medical Research Council Committee on the Aetiology of Chronic Bronchitis. Definition and classification of chronic bronchitis for clinical and epidemiological purposes. Lancet 1965; ; classificat $775-9$.

21 Baker RJ, Nelder JA. The GLIM system manual. Release 3. Oxford: Numerical Algorithms Group, 1978.

22 Anderson HR, Bland JM, Patel S, Peckham C. The natural history of asthma in childhood. J Epidemiol Community Health 1986;40:121-9.

23 Strachan DP. The childhood origins of adult bronchitis in a British cohort born in 1958 (the national child development study). London: School of Hygiene and Tropical Medicine, University of London, 1986. $123 \mathrm{pp}$. (MSc thesis.)

24 Watkins CJ, Burton P, Leeder S, Sittampalam Y, Wever AJM, Wiggins R. Doctor diagnosis and maternal recall of lower respiratory illness. Int $\mathcal{F}$ Epidemiol 1982;11:62-6.

25 Goodall JF. The natural history of some common respiratory infections in children and some principles in its management. III: Wheezy children. $\mathcal{F}$ R Coll Gen Pract 1958;1:51-9.

26 Fry J. Acute wheezy chests. Br Med $\mathcal{J} 1961$; i:227-32.

27 Strachan DP. The prevalence and natural history of wheezing in early childhood. $\mathcal{R}$ R Coll Gen Pract 1985;35:182-4.

28 Woolcock AJ, Peat JK, Salome CM, et al. Prevalence of bronchial hyperresponsiveness and asthma in a rural adult population. Thorax 1987;42:361-8.

29 Corrao WM, Braman SS, Irwin RS. Chronic cough as the sole presenting manifestation of bronchial asthma. N Engl f Med 1979;300:633-7.

30 Anderson HR. Respiratory disease in childhood. Br Med Bull 1986;42:167-7

31 Johnston IDA, Anderson HR, Lambert HP, Patel S. Respiratory morbidity and lung function after whooping cough. Lancet 1983;ii:1104-8.

32 Mok JYQ, Simpson $\mathrm{H}$. Outcome for acute bronchitis, bronchiolitis and pneumonia in infancy. Arch Dis Child 1984;59:306-9.

33 McConnochie KM, Roghmann KJ. Bronchiolitis as a possible cause of wheezing in childhood: new evidence. Pediatrics 1984;74:1-10.

34 Peto $\mathrm{R}$, Speizer FE, Cochrane AL, et al. The relevance in adults of airflow obstruction, but not of mucus hypersecretion, to mortality from chronic lung disease. Am Rev Respir Dis 1983;128: $491-500$

35 Britten N, Davies JMC, Colley JRT. Early respiratory experience and subsequent cough and peak expiratory flow rate in 36 year old men and women. BrMed $\mathcal{F}$ 1987;294:1317-20.

(Accepted 1 December 1987)

\title{
Risk of acute non-specific upper respiratory tract infections in healthy men taking dapsone-pyrimethamine for prophylaxis against malaria
}

\author{
PHENG SOON LEE, EDWIN Y L LAU
}

\begin{abstract}
The relative risks of non-specific upper respiratory tract infections were studied in two well matched groups of military recruits to see whether dapsone-pyrimethamine (Maloprim) given as antimalarial prophylaxis was associated with immunosuppression. Mean risks of upper respiratory tract infection were $64 \%$ higher in the study group than in the controls, the largest monthly differences being recorded in the months of harder training. These findings were unlikely to have been due solely to harder training in the study group, as concurrently measured sprains (arguably more likely to have been affected) were increased by only $19 \%$. A more likely explanation was some degree of immunosuppression, physical stress possibly having a synergistic effect.

These findings suggest that travellers taking dapsone-pyrimethamine as antimalarial prophylaxis may be rendered more susceptible to commoner infections, especially when engaged in increased physical activity.
\end{abstract}

Headquarters Medical Services, Singapore Armed Forces, Singapore PHENG SOON LEE, MB, BSC, formerly staff officer in charge of preventive medicine

EDWIN Y L LAU, BSC, formerly graduate researcher, preventive medicine branch

Correspondence to: Dr Lee Pheng Soon, 4 Fourth Lokyang Road, Singapore 2262.

\section{Introduction}

Severe adverse reactions to antimalarials have been reported in previously normal people, some resulting in death or serious morbidity. Nineteen cases (six fatal) of severe cutaneous reactions were recorded among American travellers taking pyrimethaminesulfadoxine (Fansidar) with chloroquine, ${ }^{1}$ and agranulocytosis has been reported in people taking dapsone-pyrimethamine (Maloprim). ${ }^{2}$ Many authorities therefore recommend that a riskbenefit analysis should always be done before prescribing these drugs, especially for prophylactic use, the latest and most elegantly argued case being that presented by Peto and Gilks. ${ }^{3}$ This, however, implies the existence of accurate information concerning risks from less dramatic but probably more frequent unwanted effects, which are far more difficult to document than serious reactions even if suspected. Any study designed to establish these "minor" events scientifically would need to be conducted on a scale too large ethically to justify enrolling the necessary numbers of healthy volunteers outside a malarious zone. On the other hand, field trials are justifiable where there is definite risk of infection but control groups cannot be identified because prophylaxis cannot be withheld. Thus only uncontrolled field trials remain; and these often cannot detect small differences occurring in a minority of the population studied.

These difficulties have almost completely prevented study of the immunopharmacology of antimalarials in man, which is of increasing importance given the frequent use of these drugs in this age of widespread global travel. Most doctors have at one time or another been approached for prescriptions of such prophylactic drugs, often 